\title{
A ANTROPONIMIA NOS TEXTOS DOCUMENTAIS GALEGOS ATA O SÉCULO XIII
}

\author{
Ana Isabel Boullón Agrelo \\ Instituto da Lingua Galega (USC)
}

A finalidade deste traballo é examinar a evolución do tratamento da antroponimia nos textos medievais ata o século xIII, para determinar como esta parte especial do léxico se comporta nos documentos escritos en latín e nos escritos en romance. Para isto teremos en conta dous corpus diferentes: un de documentos orixinais latinos e outro, máis reducido, dos documentos en galego localizados ata 1260, para que sexan máis homoxéneos cronoloxicamente, e para pór de relevo as vacilacións propias dos primeiros textos. O grao de romanceamento existente en ambos os corpora porase de manifesto non só na evolución fonética, senón tamén no tratamento dos sufixos patronímicos, pois constitúen unha evidencia da vontade latinizante dos escribas.

\section{A ANTROPOnimia nOS TEXTOS ALTOMEDIEVAIS}

As fontes examinadas para a realización deste traballo coinciden en boa medida coas utilizadas anteriormente para unha análise máis exhaustiva da antroponimia altomedieval (Boullón 1999); pero neste caso restrinxín a selección ós documentos orixinais, cuxas lecturas foron revisadas persoalmente, ou partían de edicións considerables fiables desde unha perspectiva paleográfica (como o caso de CDCoruña). Por esa razón, do Tombo de Samos só incluín os documentos orixinais que o editor engade como apéndice (ata o ano 1207). Desta maneira o corpus é máis reducido pero máis fiable en canto á súa transmisión manuscrita.

Os documentos proceden na súa maior parte dos fondos dos mosteiros galegos: Carboeiro (CDCarboeiro), Ferreira de Pantón (CDFerreiraPantón), Ramirás (CDRamirás) e Samos (TSamos), amais doutros de Santiago (CatDocSantiago, DocSantiago1, DocSantiago2) e Coruña (CDCoruña). Deles extraéronse 2001 cadeas onomásticas, distribuídas cronoloxicamente da seguinte maneira: 
Distribución cronolóxica das cadeas onomásticas

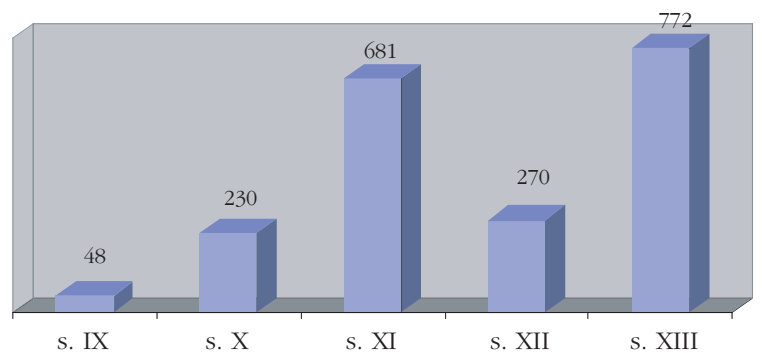

\subsection{Cara ao sistema denominativo do dobre nome}

Xa en anteriores traballos (Boullón 1995, 1999: 21-26) expuxen con certo detalle o paso do sistema do nome único á dobre denominación, que se foi producindo desde o final do séc. IX e se estendeu desde finais do XI, como ocorreu na xeneralidade da área europea cristiá. Exemplificamos o proceso con nomes tirados do noso corpus.

$\begin{array}{lll}\text { Spanosindus abbas } & \text { a.898 } & \text { DocSantiago1 I 43 } \\ \text { Felix abba } & \text { a.936 } & \text { CDCarboeiro 243 } \\ \text { Honoricus } & \text { a.937 } & \text { DocSantiago2 395 } \\ \text { Hermegotoni abbatisse } & \text { a.951 } & \text { TSamos 229 }\end{array}$

Non é agora o momento de volver sobre as causas do cambio do sistema, simplemente constataremos que o segundo nome era case sempre patronímico, e esta propiedade marcábase mediante dous procedementos maioritarios: o xenitivo latino e os sufixos patronímicos. En documentos orixinais aparecen no século x:

$\begin{array}{lrl}\text { Batinus Guand\{ilani\} } & \text { a.937 } & \text { DocSantiago2 } 395 \\ \text { Fofo Aldianiz } & \text { a.[954] } & \text { CDCarboeiro 247 } \\ \text { Kintila Argimundiz } & \text { a.[-961] } & \text { CDCarboeiro 253 } \\ \text { Pelagius Gundesaluiz } & \text { a.[-961] } & \text { CDCarboeiro 253 } \\ \text { Froyla Ariunfiz } & \text { a.975 } & \text { TSamos 141 } \\ \text { Gundissalbo Menendiz (monagis de Sancta Marina) } & {[\text { s.10] }} & \text { CDCoruña 28 } \\ \text { Ilduara Ennegiz } & {[\text { s.10] }} & \text { CDCoruña 28 } \\ \text { Odrocia Menendiz } & {[\text { s.10] }} & \text { CDCoruña 28 } \\ \text { Aloyto Teodefrediz } & {[\text { s.10] }} & \text { CDCoruña 28 } \\ \text { Gontina Fafilaz } & {[\text { s.10] }} & \text { CDCoruña 28 } \\ \text { Gudesteus Didaz (tius meus) [Etxmerilo] } & {[s .10]} & \text { CDCoruña 28 }\end{array}$


Non eran, con todo, os únicos procedementos: aparecerán os sobrenomes delexicais e, en ocasións, unha terceira designación persoal, que adoita ser unha denominación de orixe; ademais, unha constante nos documentos medievais é, como é sabido, a variabilidade, que se manifesta coas distintas maneiras de expresar o patronímico (xenitivo, fórmula proles, sufixo -z coas variantes -izi, -ici, -it, e mais adxunción simple do segundo nome):

$\begin{array}{lll}\text { Albaro prolis Gudesteiz } & \text { a.1021 } & \text { CDCoruña 33 } \\ \text { Sarracino Nuni } & \text { a.1050 } & \text { TSamos 287 } \\ \text { Arias Luzi cognomen Maza } & \text { a.[1065] } & \text { CDCoruña } 80 \\ \text { Donnino Abdelaz } & \text { a.1074 } & \text { TSamos 210 } \\ \text { Petru Iohannis de Aurantes } & {[\text { s.12] }} & \text { CDCarboeiro 548 } \\ \text { Garcia Uelasquizi } & \text { a.1110 } & \text { CDCarboeiro 281 } \\ \text { Marine Arie } & \text { a.1140 } & \text { CDCarboeiro 292 } \\ \text { Pelagius Barragam } & \text { a.1170 } & \text { TSamos 482 } \\ \text { Martin Benedictiz = Martín Benedicto } & \text { a.1236 } & \text { CDFerreiraPantón 27 }\end{array}$

Partindo dos datos que nos ofrecen os documentos orixinais examinados, elaborouse o cadro no que se constata o ritmo ascendente da evolución do dobre nome en Galicia ao longo do período altomedieval.

Evolución do dobre nome

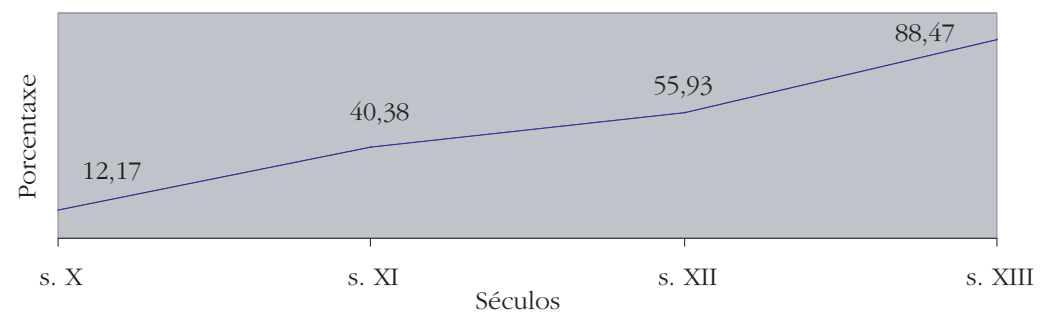

Os estudos antroponímicos que parten dunha perspectiva histórica ou sociolóxica afirman que o patronímico se xeneralizou a partir da súa adopción polos grupos dominantes, e que se poden apreciar distintas prácticas na individuación dos distintos grupos sociais; así, o nomen paternum non é utilizado en Galicia durante os ss. x e XI polos servos, por as súas condicións de dependencia impedírenlle constituír unha familia, nin polos clérigos, que se apartan do matrimonio (Martínez Sopena 1995: 402) e, por outro lado, "el empleo de los apodos, minoritario frente a las otras formas de designación, es mayor en la antroponimia servil que en la de los hombres y mujeres libres, y en la servil masculina que en la femenina" (Carzolio 2002: 171). Co 
paso do tempo, a urbanización crecente das poboacións do norte hispánico desde o xiII leva a preferir formatos de designación máis variados e cun maior contido informativo: o nome máis un elemento complementario moi determinante, como pode ser o alcume, a indicación profesional ou un topónimo de orixe. De ser o procedemento exclusivo nos séculos x e XI, pasa a diminuír significativamente nos seguintes, nunha tendencia que irá aumentando na Baixa Idade Media.

Presenza do patronímico como segundo nome

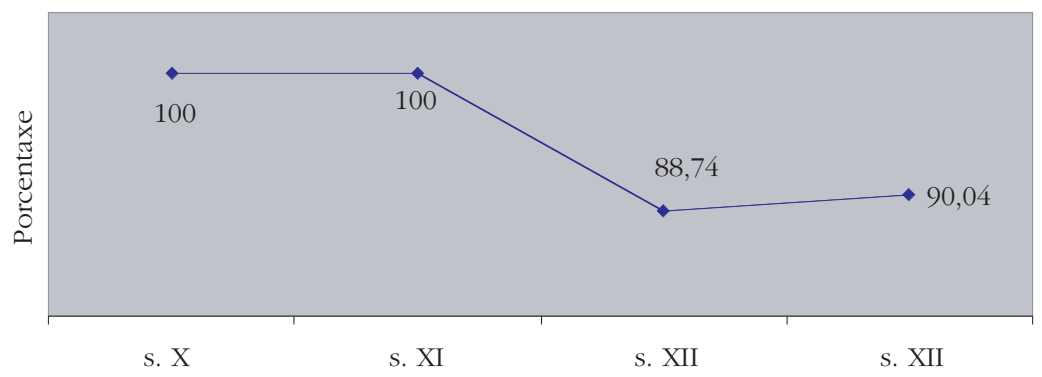

\subsection{O romanceamento das marcas patronímicas}

Interésanos distinguir os distintos procedementos patronímicos, porque eles deitarán luz sobre a vontade latinizante dos escribas. Centrarémonos en dous: a utilización do uso do sufixo patronímico e mais do xenitivo; destes, a maior parte é en $-i$, pois son nomes de orixe latina ou greco-latina declinados pola segunda declinación (ou de procedencia xermánica adaptados a este modelo); os da terceira, en -is, son case sempre do nome de orixe hebrea Iohannes:

$\begin{array}{ll}\text { Ueremudo Adefonsi } & \text { a.960 CDCarboeiro 252 } \\ \text { Sisnando Luzi } & \text { a.1000 CDCarboeiro 259 } \\ \text { Iohan Iohannis } & \text { a.1192 TSamos 487 }\end{array}$

É escusado dicir, por sabido, que non hai unha sucesión cronolóxica perfecta entre eles, dado que coexisten incluso dentro dun mesmo documento, pero si se pode advertir certas tendencias que en ocasións parecen contraditorias cos resultados romances, e que analizaremos a seguir. O que importa agora, desde o punto de vista da presenza do romance nas escrituras, é que o sistema do xenitivo debeu ser exclusivo dos textos escritos, pois non deixou descendentes na antroponimia moderna. Entón, foi coexistindo en distinta medida co sufixo patronímico, que podía presentar formas diver- 
sas. A forma máis estendida era $-z$ (-iz nas variantes máis arcaicas, -ez nas máis evolucionadas ${ }^{1}$, e coa variante $-a z$ se se trata dun nome rematado en $-a^{2}$, ou en grupo consonántico como consecuencia da evolución fonética ${ }^{3}$ ), pero tamén se documentan outras que trataremos a seguir.

- Sufixo -iz

Pelagio Suariz

Albaro prolis Gudesteiz

Ero Uelasquiz

- Sufixo -az

Sedeges Vistellaz

Piniolus Froilaz

Donnino Abdelaz

Didago Uimaraz
a.1001
TSamos 457
a.1021
CDCoruña 33
a. 1050
TSamos 287

O patronímico en -it ten unha clara intención latinizante, pois o seu uso debeuse dar por lembrar as palabras latinas rematadas en - $t$ (certos substantivos, como caput, e, sobre todo, a terceira persoa do singular dos verbos); ademais, o <z>, o grafema máis usual para representar o fonema africado predorsodental sonoro, procedía de kJ e tamén, polo que a nós nos interesa aquí, de TJ. Atopámolo por primeira vez nun exemplo illado do s. IX e, despois, un uso minoritario pero constante:

- Sufixo -it

$\begin{array}{lll}\text { Furtunit } & \text { a.898 } & \text { DocSantiago1 I } 42 \\ \text { Didacus Froylet alferit } & \text { a.1137 } & \text { CDRamirás 183 } \\ \text { Gimara Pait } & \text { a.1193 } & \text { CDRamirás 185 } \\ \text { Eluira Munit [monxa] } & \text { a.1238 } & \text { CDRamirás 204 } \\ \text { Fernandus Gondisaluit } & \text { a.1243 } & \text { CDRamirás 211 }\end{array}$

1. Aínda que no corpus de documentos latinos só se rexistra na forma Gomez: domno Gomez Transtamar et Sarriam tenente a.1196 TSamos 222, Fernando Gomez a.[1222] CDRamirás 189, Petro Gomez a.[1222] CDRamirás 189, Fernandus Gomez a.1248 CDRamirás 241.

2. Excepto en Diaz ou variantes, en que a terminación procede da evolución do xenitivo latino Didaci, que coincide formalmente co resultado do patronímico (exemplo: Suarius Didaz a.1072 TSamos 468).

3. Como en Martinz (Pelagius Martinz a. 1135 CDCarboeiro 290), ou outros que non chegaron a hoxe, como Segeredo Tetonz a.[1025] DocSantiago2 403, Oduario Alianz a 1123 CDCarboeiro 287, ou Rodrico Romanz a.1140 CDCarboeiro 290. 
Non cabe dúbida de que no seu uso tiveron que influír hábitos escriturarios, pois no noso corpus de documentos orixinais, fóra desa manifestación temperá, só se atesta nunha fonte, nos documentos de Ramirás (aínda que usado por distintos notarios: Geraldus, Gumicius, Petrus Iohannis, Petrus Menendi).., pero isto débese probablemente ás características específicas do corpus usado, posto que no documentos romances do século xIII, como despois veremos, aparece usado en diferentes mosteiros e anos.

A partir de toda esta casuística elaborei un novo cadro, coa clasificación dos tipos de patronímico e seguindo a súa aparición cronolóxica nos textos orixinais.

\section{Tipos de patronímico}

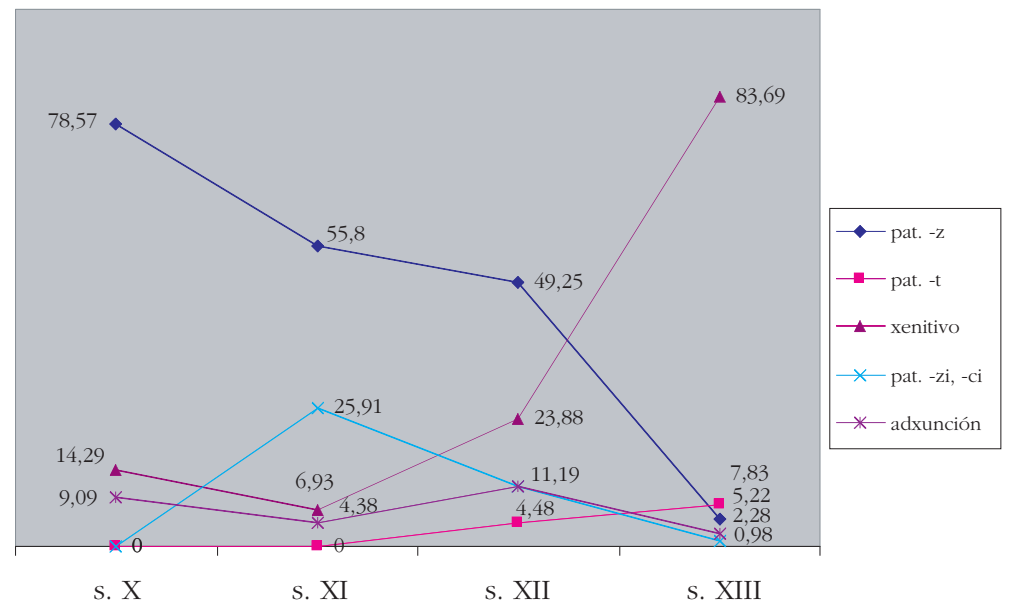

Advertimos neste gráfico varias tendencias que poden parecer contraditorias cos resultados actuais, pero que en realidade están transparentando outro fenómeno ao que despois faremos referencia. A aparición do patronímico é masiva co sufixo - $z$, xa no século x (case un 79\%), aínda que coexiste coa expresión máis latinizante, o xenitivo, cun 14\% ${ }^{4}$. No séc. XI a situación comeza a mudar: a porcentaxe do sufixo -z comeza a descender e irrompen con forza (acadan case un 26\%) variantes con fasquía máis latina, rematadas en -izi, das que reproduzo algúns exemplos tirados de fontes diversas:

4. Outro procedemento, que non aparece no gráfico por resultar irrelevante para a porcentaxe, é o uso de proles (Ueremudus prolix Silonia a.958 CDCarboeiro 251), que só no séc. XI acada unha porcentaxe significativa (un 6\%), moitas veces en unión con outros procedementos, coma o sufixo patronímico (Marina prolis Uermuizi a.1064 TSamos 195) ou o xenitivo (Orroka prolis regia Fredenandi principis a.1075 DocSantiago2 411); como se ve claramente neste último exemplo, está asociado ás clases máis nobres. En todo caso, desaparece no séc. xı definitivamente. 
- Sufixo -izi

$\begin{array}{ll}\text { Esemena Esemenizi } & \text { a.1001 TSamos } 456 \\ \text { Fromangu Sendiniz = Sendinizi } & \text { a.1001 TSamos } 457 \\ \text { Trodilli Uistrarizi } & \text { a.[1014-1036] CDCoruña } 49 \\ \text { Didago Uimarizi } & \text { a.[1088] CDCarboeiro 275 } \\ \text { Menendus Gundisaluizi = Mendu Gondisalbizi } & \text { a.1058 TSamos } 460 \\ \text { Egika Eriquizi } & \text { a.1058 TSamos } 458 \\ \text { Flamula Guterriz = Guterrizi } & \text { a.1058 TSamos } 461 \\ \text { Exemena Suarizi } & \text { a.1110 CDCarboeiro 281 } \\ \text { Arias Pelagizi pr. } & \text { a.1153 CDCarboeiro 299 } \\ \text { Petro Gomeizii = Petrus Gomezii } & \text { a.1256 CDRamirás 327 }\end{array}$

Inclúo para os datos numéricos neste grupo a variante en -ici, dado que é moi minoritaria $(0,36 \%$ no XI, $3,76 \%$ no XII e $0,16 \%$ no XIII), e coido que no fondo ambas as dúas son variantes (construída unha a partir do xenitivo dos moi abundantes nomes xermánicos rematados en -icus, e a outra con influencia do patronímico en $-z$ ).

- Sufixo -ici

Munio Nunici

Marina Ramirici

domna Maria Uermudici

Rodericus Monnici

Terasie Froiaci a.1075 DocSantiago2 411

a.1108 CatDocSantiago2 112

a.1199 CDCarboeiro 547

a.1232 CDRamirás 196

a.1250 CDRamirás 267

No XII, a tendencia continúa: mentres baixa o sufixo en $-z$, ascende o uso do xenitivo e aparece o sufixo - $t$, tamén con aparencia máis latina. Finalmente, no xIII, o xenitivo é o procedemento maioritario, con moito, e os outros todos quedaron relegados a porcentaxes pequenas, dentro das cales o maior é o sufixo $-t$; o sufixo $-z$ non chega ao $3 \%$ das ocorrencias. Outro dos procedementos tidos en conta é a simple adxunción do nome do pai, sen ningún tipo de marca, coma nos seguintes exemplos.

- Adxunción sen marca do nome do pai

Tannito Dominico

Ero Luzu

Petro Gartja

Didacus Adefonso

$\mathrm{M}<\mathrm{e}>$ ndo Laurencio a.961 TSamos 448

a.1058 TSamos 460

a.1062 CDCarboeiro 263

a.1062 CDCarboeiro 264

a.1240 CDRamirás 207 
Este procedemento aplícase, sobre todo, ós nomes da primeira declinación e, dentro da segunda, maioritariamente a Adefonsus e Laurentius. Ao meu ver, no que se refire ós nomes da segunda, é un ensaio, que en Galicia non cadrou (a diferenza doutras áreas, coma Cataluña), non sendo en dous nomes, Afonso e Lourenzo, por razóns probablemente eufónicas (de feito, hoxe en día son apelidos que carecen de sufixo). En canto á súa porcentaxe na Alta Idade Media, mantense en valores discretos (nunca máis do 12\%), e diminúe tamén no XIII, posiblemente por ser considerado demasiado 'romance'.

¿Cal é a razón deste repunte dos procedementos patronímicos máis latinizados, e a aparente decadencia do sufixo en $-z$ ? Sen dúbida non se pode desligar este proceso do que tamén ocorre no léxico, por exemplo, como constata Varela Sieiro neste mesmo volume ("Dos usos latinos aos usos romances: o tratamento do léxico"): a reaprendizaxe do latín clásico, que chegou a Galicia por man da orde de Cluny, en relación coa reposición do dereito romano que parte de Boloña e a substitución da liturxia visigótica pola romana (a. 1080) e que, en última instancia, comportaría a aparición do romance, ao aumentar considerablemente a distancia entre a lingua escrita e a lingua falada. En todo caso, o que estes datos demostran é que nos sufixos patronímicos houbo unha tendencia, que só puido ser consciente (pois os datos romances demostran que esas formas latinizadas non deixaron descendentes na lingua viva), que tentaba devolverlle ós patronímicos unha aparencia máis latina. Este esforzo por parte dos escribas non tivo correlato noutros aspectos lingüísticos, como a seguir veremos, nin éxito, pois no século xIII acabaría impóndose o romance definitivamente.

\subsection{Formas romanceadas nos lexemas antroponímicos}

Para completar a panorámica do romanceamento nos nomes propios examinei ata qué punto estes transparentan trazos romances. É ben sabido que nestes textos antigos ou primitivos debemos afrontar o problema, de non sempre doada solución, de decidir a súa adscrición lingüística, entre o latín e o romance. Xa outras veces se ten discutido sobre isto diante de textos moi temperás con abundancia de formas romances ${ }^{5}$, e tamén se ten feito un achegamento minucioso ós distintos aspectos lingüísticos que van demostrando o agromar do romance nos documentos latinos (Lorenzo 2003, 2004b: 33-36). Nesta ocasión o meu interese é comprobar como vai avanzando o romance neste ámbito tan específico da lingua como é a antroponimia. Débese ter en conta a especificidade da onomástica con respecto ao léxico

5. Véxase a interesante polémica entre Martins (1999, 2001, 2004) e Emiliano (2003c). 
común: é habitual que sexa aquí onde menos se transluza o fervor cultista (ou latinista) dos escribas, pois moitos apelidos e topónimos non teñen equivalente en latín (ou esta non é coñecida polo escriba), e, por outra parte, a necesidade de identificar sen confusións os suxeitos que participan nos actos xurídicos agudiza a fidelidade á forma real. Porén, non deixan de pesar os hábitos escriturarios que levan consigo, por exemplo nos usos das abreviaturas, o peso das formas latinas. As dúas tendencias están presentes xa desde a Alta Idade Media nos documentos.

Por tanto, para aclarar o criterio establecido á hora de considerar romanceados os ítems antroponímicos, marquei como tales aquelas formas nas que se pode apreciar algún cambio fonético explicable polo romance. Non teño en conta, en consecuencia, as variables casuais, estean ben empregadas ou non, senón só aqueles fenómenos fonéticos que transparentan a evolución da lingua (sonorización das consoantes xordas intervocálicas, caída das consoantes sonoras na mesma posición, simplificación do -nn- e do -ll-, caída do -n-, presenza das consoantes novas que indican o novo sistema de fricativas ou africadas (coma o $z$ ), metáteses, caídas de vogais pretónicas ou postónicas, etc.), tal e como se ve nas seguintes cadeas onomásticas:

$\begin{array}{lll}\text { Afriganus pr. } & \text { a.898 } & \text { DocSantiago1 I } 43 \\ \text { Sauarigo } & {[\text { s.10] }} & \text { CDCoruña 28 } \\ \text { Baronzle\}lo } & \text { a.940 } & \text { CDCarboeiro 245 } \\ \text { Adosinda Diaz } & {[\text { s.11-12] }} & \text { CatDocSantiago 111 } \\ \text { Sauarico Enegoniz } & \text { a.975 } & \text { TSamos 141 } \\ \text { Belito } & \text { a.1058 } & \text { TSamos 461 } \\ \text { Rabinato Nuniz } & \text { a.1123 } & \text { CDCarboeiro 287 } \\ \text { Petrus Romeu } & \text { a.1238 } & \text { CDRamirás 204 } \\ \text { Petro Moacho } & \text { a.1247 } & \text { CDFerreiraPantón 31 }\end{array}$

Cabe destacar aquí que hai algúns nomes de moi alta frecuencia que amosan calquera destes fenómenos ${ }^{6}$ :

Fredenandus

$\begin{array}{lll}\begin{array}{l}\text { Arias Fernandiz } \\ \text { Fernando Altarizi } \\ \text { unno }\end{array} & \text { a.1001 } & \text { TSamos } 457 \\ \text { Moniu Nunizi } & \text { a.1001 } & \text { TSamos } 457 \\ \text { Nuno Uermudiz } & \text { a.1050 } & \text { TSamos } 457 \\ \text { Iohanni Nuniz } & \text { a.1170 } & \text { TSamos 287 } \\ \end{array}$

6. Para as etimoloxías correspondentes, véxase Boullón 1999. 
Munnio

$\begin{array}{lll}\text { Monio } & \text { a.985 } & \text { TSamos } 453 \\ \text { Fafila Muniz } & \text { a.1075 } & \text { DocSantiago2 412 } \\ \text { Monnio Ordoniz } & \text { a.1104 } & \text { TSamos 220 }\end{array}$

O cadro que a seguir presentamos contempla, logo, calquera de estes fenómenos, que afastan o ítem antroponímico da súa forma máis etimolóxica.

O romanceamento na antroponimia

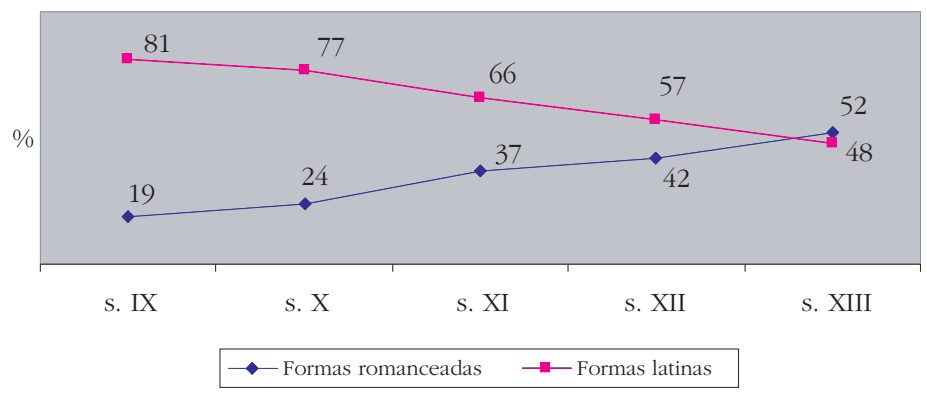

Formas completamente en galego son escasas, en realidade; atéstanse todas elas no séc. XIII e na súa maioría foron escritas polo mesmo notario, $P e$ trus Menendi:

\begin{tabular}{l|c|l|l}
\cline { 2 - 4 } & Ano & \multicolumn{1}{c}{ Fonte } & \multicolumn{1}{c}{ Notario/escriba } \\
\hline Fernando Gomez & a.[1222] & CDRamirás 189 & Fernando Ruderici existente notario \\
\hline Maria Diaz & a.1225 & CDRamirás 192 & Iohannes notuit \\
\hline Oruelido [monxa] & a.1234 & CDRamirás 199 & (sen nome) \\
\hline Saluador pr. (don) & a.1239 & CDRamirás 205 & Petrus Menendi notarius de Milmanda \\
\hline Bel_Infante & a.1240 & CDRamirás 207 & Petrus Menendi publici notarii de Milmanda \\
\hline Saluador Nariz pr. & a.1243 & CDRamirás 212 & Petrus Menendi notarius de Milmanda \\
\hline Maor Ueegas & a.1256 & CDRamirás 325 & Petrus Iohannis qui notuit \\
\hline
\end{tabular}

Destas dúas análises, o comportamento dos procedementos patronímicos e o romanceamento dos lexemas onomásticos, podemos inferir que os intentos de latinización consciente se aplicaron só nos primeiros, pois a maneira de expresar a filiación non presentaba problemas de identificación dos personaxes: tanto ten escribir Moniz ca Monizi, Gondisaluizi ca Gondisaluiz ou Gondisalui, Arias ca Arie, Lupe ca Lupiz ou Lopiz (formas todas estas que alternan nos textos). Sen embargo, dá a impresión que o romanceamento dos lexemas é un proceso imparable que comeza no Ix e que no séc. XIII é xa 
maioritario: nesta altura, hai xa máis formas con trazos romances cás que están escritas en latín correcto. Nos textos xa escritos en galego persistirían algúns procedementos patronímicos latinizados, pois moi forte era a tradición, pero quedaron poucos lexemas latinizados.

\section{A ANTROPOnimia Nos DOCUMENTOS EN GALEGO DO SÉCUlO XIII}

Como fonte para o estudo dos antropónimos en documentos notariais escritos en galego no século XIII, partín dun corpus de 34 documentos, procedentes de 17 lugares diferentes, na súa maior parte centros monásticos, datados entre 1228 e 1260. Proporcionaron un total de 745 cadeas onomásticas. As referencias completas de cada documento son dadas en Boullón 2004. Todos eles son documentos orixinais, excepto dous traslados moi próximos na data de confección:

- doc. de 14/9/[1255], Caaveiro, copiado no Tombo (TCaaveiro), feito na década de 1250 .

- doc. de 3/12/[1240], de Vilar de Donas, copiado en 1241.

Se ben case todos foron xa editados, as lecturas foron todas revisadas, pois van ser obxecto dunha edición específica (Boullón / Monteagudo no prelo). Isto motivou algún cambio de datación, que será explicado no devandito libro; téñase en conta, en todo caso, que as posibles oscilacións temporais non afectan para o conxunto, pois todos eles se sitúan dentro do marco cronolóxico establecido. A continuación damos as datacións concretas, a data tópica ${ }^{7}$ e a súa referencia arquivística.

\begin{tabular}{l|l|l}
\hline Ribadavia & $1228 ?$ & ACOu \\
\hline Allariz & {$[1230-1250]$} & Arquivo da Casa de Alba \\
\hline Melón & 1231 -agosto-25 & AHN, Clero. Ourense, Melón, carp. 1441/4 \\
\hline Melón & 1233 -febreiro-4 & $\begin{array}{l}\text { AHN, Clero. Ourense, Melón, carp. } \\
1441 / 11\end{array}$ \\
\hline Sobrado / Almerezo (Ponteceso) & $1234-1236$ & ARG, perg. $n^{\circ}$ 312 \\
\hline Vilar de Donas & {$[1240]$-decembro-3 } & AHN, San Marcos, carp. 390/199 \\
\hline Penamaior & 1241 -setembro & AHN, Clero, 1216/9 \\
\hline Sobrado & {$[1242-1252]$} & ARG, perg. n ${ }^{\circ}$ 112 \\
\hline Ferreira de Pallares & {$[1243]$} & AHN, Clero, 1082/18 \\
\hline Allariz / Vilaboa (A Veiga) & 1244 -xaneiro & AHPOu, Sta. Clara de Allariz.
\end{tabular}

7. Utilizáronse varios criterios: o mosteiro onde tivo lugar o acto xurídico, o lugar concreto que o protagoniza (separado cun signo /); e o lugar de actuación do notario, non todos eles explícitos en cada documento. 


\begin{tabular}{|c|c|c|}
\hline Ferreira de Pallares & 1247-abril-6 & $\begin{array}{l}\text { AHN, Clero, Lugo, Ferreira de Pallares, } \\
1086 / 3\end{array}$ \\
\hline Montederramo & 1250 & AHPOu, Montederramo, carp. C-9, $\mathrm{n}^{\circ} 2$. \\
\hline Castañeira (Zamora) & 1251 & AHN, Carp. 2339, perg. 47. \\
\hline Allariz / Sindín & 1251-novembro-27 & AHPOu, Santa Clara de Allariz. \\
\hline Castañeira & 1252 & AHN, carp. 2339 , perg. 49. \\
\hline Oia & 1253-xullo-8 & AHN, Clero, Oia, carp. 1801, nº 9 \\
\hline Meira & 1254-setembro & AHN, Clero, Meira 1134/20 \\
\hline Sobrado de Trives & 1255-xaneiro-22 & AHN Clero, Antealtares, carp. $521 / 4$ \\
\hline Sobrado de Trives & 1255-xullo-10 & AA, Perg. Trives, VII/ 48 \\
\hline Ferreira de Pallares & 1255-xullo-15 & $\begin{array}{l}\text { AHN, Clero, Lugo, Ferreira de Pallares, } \\
1087 / 8\end{array}$ \\
\hline Melón & 1255-agosto- 23 & AHN, Clero. Ourense, Melón, carp. 1448/2 \\
\hline Caaveiro & [1255]-setembro-14 & $\begin{array}{l}\text { AHN, cód. 1439B, fol. 56, col. 1, fol. 57, } \\
\text { col. } 2\end{array}$ \\
\hline Montederramo & 1255-setembro- 22 & AHN, Clero, carp. 1484/4 \\
\hline Melón & 1255-decembro & AHN, Clero, Ourense, Melón, carp. $1448 / 6$ \\
\hline Sobrado de Trives & 1256-marzo-1 & AA, caixón 4, mazo 2-A, nº 475 \\
\hline Monfero & 1257-abril-26 & ARG. $N^{\circ} 114$ \\
\hline Ferreira de Pallares & 1257-novembro-8 & $\begin{array}{l}\text { AHN Clero, Lugo, Ferreira de Pallares, } \\
1083 / 23\end{array}$ \\
\hline Meira & 1257-decembro- 25 & AHN, Clero, carp. $1135 / 15$ \\
\hline Ferreira de Pallares & 1258-xuño-5 & $\begin{array}{l}\text { AHN, Clero, Lugo, Ferreira de Pallares, } \\
1088 / 5\end{array}$ \\
\hline Ferreira de Pallares & 1258-setembro-17 & $\begin{array}{l}\text { AHN, Clero, Lugo, Ferreira de Pallares, } \\
1088 / 7\end{array}$ \\
\hline Xestosa (Toén) & 1259-marzo-3 & AHN, Clero, $1517 / 6$ \\
\hline Moraime & 1260-xuño-11 & Museo de Pontevedra \\
\hline Ferreira de Pallares & 1259-xuño-22 & AHN Clero, $1085 / 1$ bis \\
\hline Caaveiro & [1260-1265] & ARG, perg. no 111 . \\
\hline
\end{tabular}

O reparto non é proporcional no transcurso do tempo, como se advirte no seguinte cadro:

Distribución das cadeas onomásticas por décadas

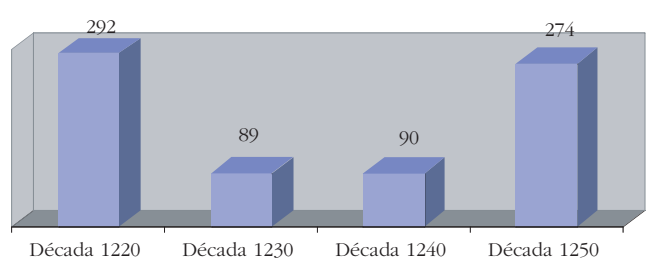


A razón da abundancia de rexistros nas primeiras décadas, de 1220 e 1230, é a inclusión de dous documentos moi longos, o foro de Castro Caldelas e mais o chamado Tombo das Viñas de Ribadavia ${ }^{8}$.

A primeira aproximación feita a este material antroponímíco foi a súa clasificación lingüística: nestes primeiros documentos romances, xunto coas formas propiamente romances, maioritarias, perduran aínda bastantes formas latinas (un 16,5\%), e formas máis ou menos híbridas (quérese dicir, desinencias casuais latinas en lexemas romances, ou un patronímico romance tras un prenome en latín, ou, á inversa, un prenome en romance máis un patronímico en latín). O resume das porcentaxes vese no cadro seguinte, e a continuación, uns exemplos da diferente casuística atopada.

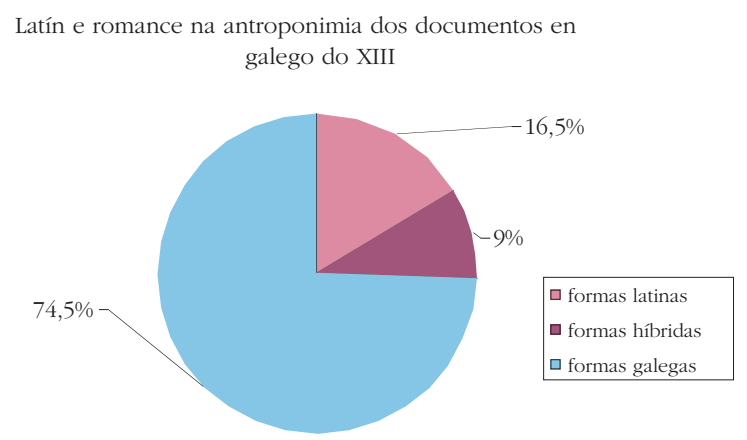

- Antropónimos en latín

$\begin{array}{lll}\text { Rod }<\text { er }>\text { ic }<\text { us }>\text { P }<\text { e }>1<\text { a }>\text { gij } & \text { 1230-1250 } & \text { Allariz } \\ \text { Michael Roderici pr }<\text { e }>\text { sb }<\text { iter }> & \text { 1244-xaneiro } & \text { Allariz / Vilaboa (A Veiga) } \\ \text { Martin<us }>\text { Velascj } & \text { 1251-novembro-27 } & \text { Allariz / Sendín } \\ \text { Michael Iohannis } & \text { 1257-novembro } & \text { Ferreira de Pallares } \\ \text { P }<\text { elag }>\text { lij Joh }<\text { ann }>\text { is } & \text { 1259-xuño-22 } & \text { Ferreira de Pallares }\end{array}$

- Prenome en latín + segundo nome en galego

$\begin{array}{lll}\text { Valasco M<ar>tiz } & \text { 1247-abril-6 } & \text { Ferreira de Pallares } \\ \text { Petr }<\text { us }>\text { Gil } & \text { 1250-febreiro } & \text { Montederramo } \\ \text { Ianuari Paez } & \text { 1251-novembro-27 } & \text { Allariz / Sendín }\end{array}$

8. O primeiro foi transcrito por Henrique Monteagudo (véxase Monteagudo 2005 e no prelo; o mesmo autor ofrece a transcrición do texto en http://www.consellodacultura.org/mediateca/ pubs.pdf/doc_en_galego.pdf) e o segundo por Luz Méndez, quen amablemente nos proporcionou a súa edición (e fai un estudo sobre el neste mesmo volume). Téñase en conta que no Tombo de Ribadavia só se tivo en conta o lado da carne, xa que o pelo é do xIV, segundo me informa a súa editora; a súa data é aproximativa, pois non aparece explícita no texto. As datacións son aproximativas en ambos e dous casos, e poden abranguer un período cronolóxico de finais da década de 1220 a 1250 . 
- Prenome en galego + segundo nome en latín

Fernã Martiniz

Domĩga Pet $<\mathrm{r}>\mathrm{i}$

Mig<ue $>1$ Ioh<anne $>$ s de Zole

Johã Michaeliz Neto

- Romanceamentos

Lourentio Paez

Ferreyrus

Guillemj abbas Mõte Ramj 1244-xaneiro

1251-novembro-27

1258-setembro-17

1254-setembro
Allariz / Vilaboa (A Veiga)

Allariz / Sendín

Ferreira de Pallares

Meira

Ribadavia

Melón

Allariz

- Antropónimos en galego

Johan Abellõ

Maria do Curral

Pay d' Oliueira

Pedr' Ianes Ceboleiro

Pay Martiz scelareyro

Gomez Pedrez caualejro

Domĩgo Lourẽ o

Nunu Eanes de Moosende

$\mathrm{P}<e d r o>$ Cabeza

Johã Meẽdez
$1228 ?$

1255-agosto-23

1230-1250
1230-1250

1228 ?

1228 ?

1228 ?

1231-agosto-25

1252

1254-setembro

1255-xullo-15

1257-novembro

1259-marzo-3
Allariz

Ribadavia

Ribadavia

Ribadavia

Melón

Castañeira

Meira

Ferreira de Pallares

Ferreira de Pallares

Xestosa (Toén)

A latinización na antroponimia en textos romances (porcentaxe)

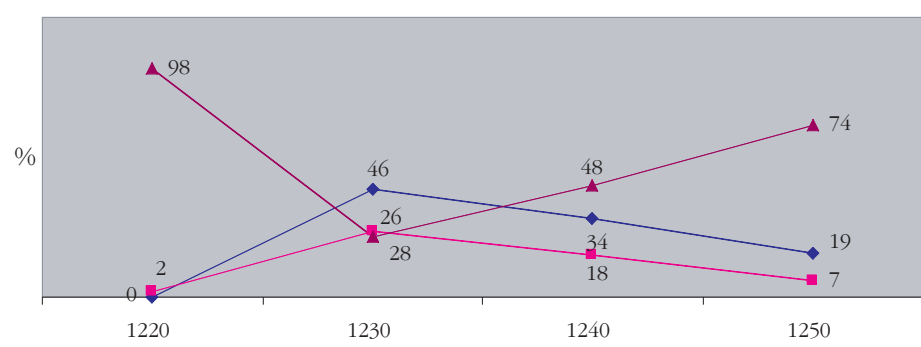

$\longrightarrow$ Formas latinizadas $\quad \longrightarrow$ Formas híbridas $\quad$ Formas romances

Do cadro infírese unha tendencia non progresiva, sobre todo o que atinxe á primeira década. O feito de tódalas ocorrencias do tombo das viñas de Ribadavia estaren en romance, nun texto de datación dubidosa, podería ser indicativo de datación máis tardía. A partir da década de 1230 si que hai unha progresión máis nidia: van diminuíndo as formas latinas e híbridas e 
aumentando as romances. De todas formas, non se pode falar de tendencias claras nestes documentos, moi heteroxéneos en canto á tipoloxía e ao lugar de redacción. Se temos en conta, por exemplo, o mosteiro de Ferreira de Pallares, que é o que conta con máis documentos romances nestas datas, veremos que os distintos notarios non actúan de forma uniforme: en xeral advírtese en case todos eles a presenza de formas galegas, maioritarias, e latinizantes, minoritarias; pero algúns escribas, como Johan de Santiago, notario de Portomarín (1256), escriben tódalas formas en galego, e outros, como Petrus Iohannis (1257), que as escriben máis en latín; e os dous últimos, de 1258 e 1259, escritos por Johannes de Leiro e Fernandus, respectivamente, xa volven a ofrecernos esa mestura de formas galegas e latinas. En Melón, o escriba do documento máis antigo, de 1231, Pedro Rodríguez dito Manteiga, tende a escribir os nomes en galego (Pay $M<a>r t<i z>$ scelareyro, Ff<ernando> Capelo subcelareyro), máis co de 1233, Petrus Petri ( $J<$ obannes > cellarius); en xeral, hai máis proporción de formas galegas no mosteiro de Melón ca no de Ferreira.

Non parece, pois, que se trate dunha cuestión estritamente cronolóxica, senón que máis probablemente teña que ver coa formación de cada un dos notarios e dos hábitos escriturarios dos que parten. Son mostras das flutuacións normais nunha época de cambio, "dunha escrita nacente, dubidosa de se desprender da vestimenta latina e procuradora de solucións gráficas axeitadas á realidade romance da que son reflexo" (Tato Plaza 1997: 297).

\subsection{O sistema de denominación nos documentos romances do s. XIII}

No que respecta ao sistema denominación nestes documentos, confírmase, loxicamente, o xa visto para os documentos latinos do mesmo período: o dobre nome aquí é do $87,5 \%$, practicamente o mesmo ca o dos documentos latinos, do 88\%. Cómpre ter en conta que o nome único é dado ós dous estremos da escada social: por un lado, a señores, nobres, ou eclesiásticos, e que por tanto son identificados polo seu cargo ou posición?; por outro lado, a persoas que só levan un alcume.

- Nomes de señores, nobres ou altos postos na corte

Alfonso rey de Leon (don)

Aldonza filie regis

Sancia [filie regis]
Abril (dõ)

Aras (don)

Froya conde (don)

9. A porcentaxe de nomes únicos aumenta por incluír o foro de Caldelas, un documento real no que figuran moitos altos cargos, e, por razón inversa, o Tombo de Ribadavia, no que hai persoas designadas só con alcume. 


$\begin{array}{ll}\text { Mateu (dõ) } & \text { Orracha (don') } \\ \text { Petri (domini) } & \text { Sancha (dona) } \\ \text { Petri (domnus) } & \text { Serra (dona) } \\ \text { Vicente (dõ) } & \text { Steuaina (dona) } \\ \text { Viuiã (dõ) } & \text { Teresia (dona) } \\ \text { Petrus cãcellarius domini regis } & \text { Toda (dona) } \\ & \\ \text { - Eclesiásticos } & \\ \text { Bernaldus archiepiscopus compostellanus } & \text { magister Moniois auriensis } \\ \text { Johannes episcopus in Auria } & \text { abbas ĩ Meyra dõ Heymerico } \\ \text { Laurẽcius aurensis episcopus } & \text { Petrus (abbas cellanouensis) } \\ \text { Stephanus tudensis episcopus } & \text { Guillemj abbas Mõte Ramj } \\ \text { dõ Micael bispu ĩ Lugu } & \text { abade dom Gomet } \\ \text { Michael lucensis episcopus } & \text { abbade dõ Esteuo } \\ \text { Martinus minduniensis episcopus } & \text { prior dõ Fernando [Caaveiro] } \\ \text { Rodericus legionensis episcopus } & \text { Johannes prior Ospitalis } \\ \text { Geraldus coriensis episcopus } & \text { Petrus prior Iuncarie } \\ \text { Johannis ouetensis episcopus } & \text { Johannes cellarius } \\ \text { Nunus astoronensis episcopus } & \text { Johannes vestiarius } \\ \text { Pelagius salamantinus episcopus } & \text { dõ Vasco uistiaro } \\ \text { Lonbaldus ciuitanensis episcopus } & \text { frey Munino celareyro de Melõ } \\ \text { Michaele (episcopo lucensi dõ) } & \text { Petrus capilam } \\ \text { Martinus zamorensis episcopus } & \text { dõ Michael [clerigo] } \\ \text { Garcia archidaconus auriensis } & \text { dõ Arias mõges } \\ \text { arcidiagóó dõ Matheus } & \text { dõ Payo mõges }\end{array}$

- Notarios ou escribas

$\begin{array}{lll}\text { Nuno clerico Sancti Iacobi notarius concilij de Allariz scripsit } & 1230-1250 \quad \text { Allariz } \\ \text { Johannes qui notuit } & 1244 \text {-xaneiro } & \text { Allariz / Vilaboa (A Veiga) } \\ \text { Bartholomeus notarius } & 1247 \text {-abril-6 } & \text { Ferreira de Pallares } \\ \text { frater Fernandus notaujt } & 1252 & \text { Castañeira } \\ \text { Fernandus qui notuit } & 1259 \text {-xuño-22 } & \text { Ferreira de Pallares }\end{array}$

- Mulleres

As mulleres, como é habitual, están moi pouco representadas nos documentos: no noso corpus constitúen só un $11,5 \%$ do total das cadeas onomásticas. O seu sistema de denominación é coma o dos homes, a grandes trazos: adoitan levar nome dobre, e as que levan nome único, ou ben son señoras (e por tanto levan o tratamento dona) ou ben son designadas con relación ao seu marido: 
Marina uxor eius [Johan Ramirt] 1244-xaneiro Allariz / Vilaboa (A Veiga)

dona Costancia (mea moler) [Munio Fernande de Rodeiro] 1258-xuño-5 Ferreira de Pallares

- Alcumes

Presentan especial interese os alcumes deste corpus, por apareceren nun número certamente significativo de casos como nome único; xa dixemos antes que comezaron a aparecer como marca de servos, e é un sistema de denominación única pouco frecuente. Nas nosas fontes están concentrados en tres documentos, o que non significa que a súa existencia se vira reducida a eses lugares, senón que posiblemente noutros simplemente non se consignase, como se pode constatar noutras fontes:

La creación del apodo es un acto social, como lo es también su fijación, pero depende de las prácticas notariales el hecho de que nos sea transmitido. Acaso a ello deberíamos atribuir su ausencia en el 'inventario' y su escasez en el TSamos, comparada con la relativa abundancia de su presencia en las listas y en los TCelanova y TSobrado (Carzolio 2002: 171).

No tombo das viñas de Ribadavia hai un rexistro de xente do pobo moito maior do que é usual nos documentos notariais, onde o habitual é figuraren, amais das autoridades e os eclesiásticos, os protagonistas dos actos xurídicos, que adoitaban pertencer ás clases sociais máis pudientes.

$\begin{array}{lll}\text { Cornellon } & 1228 & \text { Allariz } \\ \text { Pe de Queso = Ped de Queso } & 1228 ? & \text { Ribadavia } \\ \text { oleyro (fiyo del) } & 1228 ? & \text { Ribadavia } \\ \text { Barua de Lobe } & 1228 ? & \text { Rivadavia } \\ \text { Merguliõ } & 1228 ? & \text { Ribadavia } \\ \text { Colaza } & 1228 ? & \text { Ribadavia } \\ \text { Cãpiõ } & 1228 ? & \text { Ribadavia } \\ \text { Ferreyrus } & 1255 \text {-agosto-23 } & \text { Melón } \\ \text { Cutefe } & \text { 1255-agosto-23 } & \text { Melón }\end{array}$

Ó longo do século xiII vanse estendendo outras formas de segundo nome: se ben a maioritaria segue sendo a expresión patronímica, ben expresada por medio do antigo procedemento do xenitivo latino, un sufixo patronímico (-iz, -ez, e agora tamén -es, $-s)$, ou a simple adxunción do nome do pai, sen expresión de ningún tipo de marca (o que ocorre, como xa dixemos, nos nomes Lourenço e Afonso, ou noutros da primeira declinación latina como Arias, García, ou de procedencia franca, como Gil ou Durán), aumen- 
tan proporcionalmente os segundos nomes procedentes de alcumes ou con base en nomes de orixe: acadan agora un $26 \%$. Vemos o resumo no seguinte gráfico.

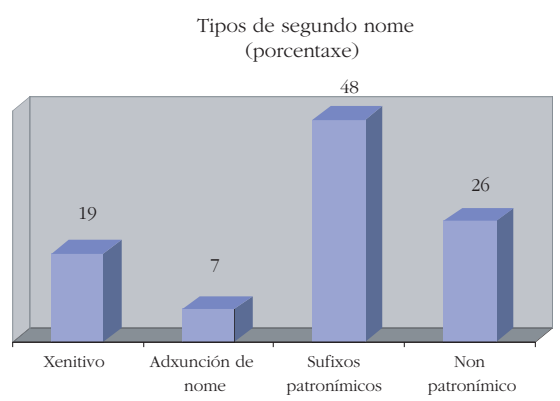

Cumpriría consignar ademais que un 14\% das cadeas onomásticas presentan un terceiro nome; deles, a maioría (o 68\%) son de designación de orixe, polo que o seu valor onomástico é dubidoso: nestes casos pode tratarse dunha atribución local momentánea para o documento en cuestión, e non dunha forma particular de denominar o individuo, como parece máis claro nos que proceden de alcumes, que son más idiosincráticos; cf. os seguintes grupos:

- $3^{\circ}$ nome de orixe

Maria Petri de Marzã

Johan L<ouren >ço da Ffonte

$\mathrm{P}<\mathrm{edr}>\mathrm{O} \mathrm{V}<\mathrm{er}>\mathrm{muez}$ Marinao [arcipreste]

1227-novembro

1228 ?

1240-setembro-14(1253)

Ferreira de Pallares

Ribadavia

Caaveiro

- $3^{\circ}$ nome delexical

Joane Moogo dito Pelõ = Joã Pelõ

Fern $<\mathrm{an}>\mathrm{P}<\mathrm{e}>\mathrm{1}<$ agii $>$ Uarella

Johã Rod[r]ig<e $>$ z Calabaza

$\begin{array}{ll}\text { 1255-agosto-23 } & \text { Melón } \\ 1228 & \text { Allariz } \\ 1255 \text {-setembro-22 } & \text { Montederramo }\end{array}$

\subsection{As marcas patronimicas nos segundos nomes}

De novo consideraremos aquí as marcas patronímicas que presentan indicios de latinización, isto é, os xenitivos da segunda declinación latina (tales como Fernandi, Martini, os máis numerosos, pois á segunda se adaptaban os frecuentísimos nomes xermánicos), mais os da primeira (Garsie, Aire) e a terceira (Iohannis); ademais, os que revelan a intención latinizante da terminación en -t do sufixo patronímico (en Uirmuit, Ramirit), e a vocal - $i$ - ante- 
cedendo ao -z do sufixo romance (como en Suariz, Petriz). Se sumamos todas estas ocorrencias, comprobamos que a porcentaxe é bastante alta (arredor do 38\%), pero minoritaria ao lado das formas puramente romances que representan a continuación do xenitivo da $3^{\text {a }}$ declinación latina (Eanes ou Anes e Saluadores), o sufixo -ez ou simplemente $-z$ en formas que presentan outras evolucións fonéticas (Martiz, Moniz) ${ }^{10}$, ou mesmo un paso adiante na evolución da sibilante final a $-s$ (Rodriges, Fernandes), forma do sufixo patronímico que aparece por primeira vez e que se convertería en maioritaria nos finais da Idade Media ${ }^{11}$. En total, estas formas plenamente romances supoñen un $62 \%$.

Tipos de marcas patronímicas en documentos romances do XIII (porcentaxe)

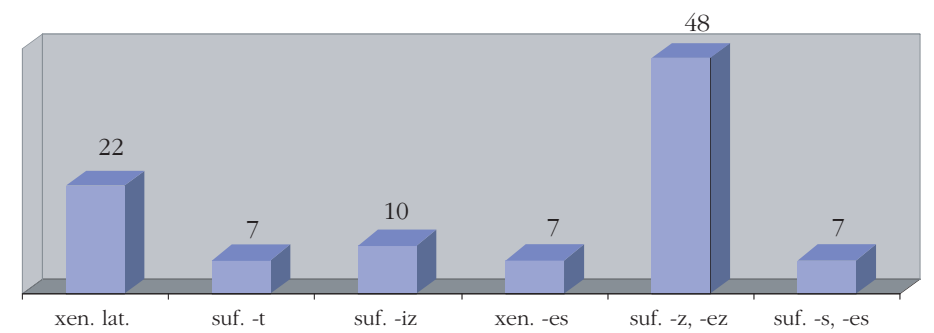

Chama a atención a pervivencia nos documentos romances do XIII do suf. - it, en textos de diversas procedencias (Melón, Sobrado, Ourense, Ferreira de Pallares, Montederramo), e distintos notarios, desde 1227 ata 1260, nunha porcentaxe idéntica á dos documentos latinos: un 7\%. A maior parte dáse na década con máis latinizacións, a de 1240.

10. Incluímos neste grupo aquelas formas abreviadas que non presentaban expresamente unha vocal, senón que era representación do editor, tales como $K<$ ohan $>P<a e>z p<r>i o l$ 1231-agosto25, Domiga $P<$ ere $>z 1255$ setembro-22, Domĩgo Mig<e $>k<e>z$ 1256-marzo-1, ou totalmente abreviado, como en Pay $M<a>r t<i z\rangle$ scelareyro 1231-agosto-25, Berto Nun<ez $>$ de Castelo 1255-xullo-15. As abreviaturas son habituais nos nomes moi frecuentes, e chegan a supor o $40 \%$ dos patronímicos con $-\mathrm{z}$.

11. Aquí só se atesta en tres fontes: a maioría das veces, no tombo das Viñas de Ribadavia (Tome Peres, Domingo Paas, Moor $M<a>r<t i>s$, ata 28 casos), tres no documento de Vilar de Donas (contra 1240), un no tombo de Caaveiro (don Goncaluo Rodriges), e un noutro de Sobrado tamén de data dubidosa, 1242-1252 (iuit Muñ̃ Fernãdit = iuit Muñ̃ Fernãdis). En todos os casos, pero sobre todo no primeiro, pode ser un argumento para considerar unha datación máis tardía. 


\begin{tabular}{|c|c|c|c|}
\hline $\mathrm{P}<$ edro $>$ Saluadorit & 1231-agosto- 25 & Melón & $\begin{array}{l}\text { Pedro Rodriguez dicto Manteyga } \\
\text { qui notey }\end{array}$ \\
\hline Gomet (abade dom) & 1231-agosto-25 & Melón & $\begin{array}{l}\text { Pedro Rodriguez dicto Manteyga } \\
\text { qui notey }\end{array}$ \\
\hline Ffernã Diat sou padre [Pidru Fernãdit] & $1242-1252]$ & Sobrado & (sen nome) \\
\hline $\begin{array}{l}\text { [Io]h<an> Pirit iscudeyro de Felgoso filio } \\
\text { di Pidru [+] }\end{array}$ & \multicolumn{2}{|c|}{$[$ Io]h $<$ an $>$ Pirit iscudeyro de Felgoso filio } & (sen nome) \\
\hline Munĩ Fernãdit (iuit) = iuit Munĩ Fernãdis & $1242-1252]$ & Sobrado & (sen nome) \\
\hline$\underline{\text { Suer [Fer]nãdit }}$ & $1242-1252]$ & Sobrado & (sen nome) \\
\hline Pidru Fernãdit = Pedru Ffernãdit & $1242-1252]$ & Sobrado & (sen nome) \\
\hline$\underline{\text { Ruy Pirit (iuit et pur notario iurado) }}$ & $1242-1252]$ & Sobrado & (sen nome) \\
\hline Petr $<$ us $>$ Sãcit miles & 1244-xaneiro & $\begin{array}{l}\text { Allariz/ } \\
\text { Vilaboa (A Veiga) }\end{array}$ & Johannes qui notuit \\
\hline Petr $<$ us $>$ Sancit & 1244-xaneiro & Allariz/Vilaboa & Johannes qui notuit \\
\hline Johan Ramirt & 1244-xaneiro & Allariz/Vilaboa & Johannes qui notuit \\
\hline Rod<er>ico Gõzalit (meirino) & 1244-xaneiro & Allariz/Vilaboa & Johannes qui notuit \\
\hline Rod<er>ico Sãcit miles & 1244-xaneiro & Allariz/Vilaboa & Johannes qui notuit \\
\hline Eluira Sancit (uxor ei) [Michael Petiz] & 1244-xaneiro & Allariz/Vilaboa & Johannes qui notuit \\
\hline $\mathrm{R}<$ roderico> Floylat (tenẽte Sariia) & 1247-abril-6 & Ferreira de Pallares & $\begin{array}{l}\text { Bartholomeus notarius [de Ulloa] } \\
\text { notuit }\end{array}$ \\
\hline L. Lupet o ck<er $>$ igo & 1250-febreiro & Montederramo & Petrus Martini que notuit \\
\hline [Elu]ira Gunzaluet & 1251-novembro-2 & 7Allariz/Sendín & $\begin{array}{l}\text { Petrus Martini das Manus qui } \\
\text { notauit testis }\end{array}$ \\
\hline Marina Froat & 1255-agosto-23 & Melón & (sen nome) \\
\hline $\mathrm{M}<$ ari $>$ a Uirmuit & 1257-novembro & Ferreira de Pallares & Petrus Iohannis qui notuit \\
\hline
\end{tabular}

\section{3. $\mathrm{CABO}$}

Nos documentos en latín ao longo da Idade Media observamos que a tendencia inicial a usar os sufixos patronímicos autóctonos $(-z$, ou a súa variante $-z i$ ), en detrimento do procedemento latino do xenitivo, vai diminuíndo a partir do séc. XI, e de maneira moi acelerada no xII. Paralelamente, aumenta o uso do xenitivo latino e, en menor medida, outros sufixos que se consideran máis latinizantes $(-t,-i c i)$. É así que nos documentos en latín do séc. XIII as formas maioritarias e en alza son esas (xenitivo: 77\%, pat. -ici, -it, cun 13\%). Sen embargo, e contraditoriamente con esta tendencia latinizante (ou pseudolatinizante), que ten que ver coa reforma do latín clásico espallada en Europa a partir do XI, hai un aumento paulatino das formas romanceadas nos lexemas antroponímicos, que chegan á máis da metade no XIII $(52 \%)$. 
Nos textos en galego deste século (ata o ano 1260), que presentan en xeral moitas formas latinas, as da antroponimia son maioritariamente romances, un 74,5\%, proporción que aínda aumentaría se tivésemos en conta soamente os documentos privados (e non o foro de Caldelas). Así mesmo, hai pervivencia das antigas formas latinizantes, aínda que en menor medida (o xenitivo, un 19\%, o - $t$ co mesmo 7\%): o máis frecuente é o sufixo en - $z$, e aparece por primeira vez a forma máis moderna e xeneralizada na Baixa Idade Media, o sufixo -es. En conxunto, os trazos arcaizantes se mostran máis nos antigos sufixos ca nos lexemas, igual ca o que se ve no textos escritos integramente en latín. É a preconfiguración do panorama real, que se plasmará de maneira moito máis evidente na literatura, como se pode comprobar no traballo dedicado á onomástica literaria medieval, feito por Déborah González, neste mesmo volume. 